\title{
Flood disasters and social resilience during the decline of the Qing Dynasty: case studies of 1823 and 1849
}

\author{
Zhixin $\mathrm{Hao}^{1}$, Dangyang Xiong ${ }^{2}$, and Jingyun Zheng ${ }^{1}$ \\ ${ }^{1}$ Institute of Geographic Sciences and Natural Resources Research, Chinese Academy of \\ Sciences \\ ${ }^{2}$ Institute of Geographic Sciences and Natural Resources Research Chinese Academy of \\ Sciences
}

February 18, 2021

\begin{abstract}
Based on historical records and crop harvest scores extracted from historical documents, this study reconstructed the spatialtemporal distribution and severities of floods in the Yangtze-Huai River valley in 1823 and 1849. We also summarized the effects of the floods on society and identified government measures taken to cope with the floods in the context of the economic recession in the period of 1801-1850. The 1823 flood, which was caused by the heavy precipitation of the Meiyu period and typhoons, severely affected areas in the lower reaches of the Yangtze River. Meanwhile, the 1849 flood, triggered by long-term, high-intensity Meiyu precipitation in the middle and lower reaches of the Yangtze River, mainly affected areas along the Yangtze River. The 1849 disaster was more serious than the one in 1823. In the lower reaches of the Yangtze River, the 1849 flood caused the worst agricultural failure of the period 1730-1852. To deal with the disasters, the Qing government took relief measures, such as exempting taxes in the affected areas, distributing grain stored in warehouses, and transferring grain to severely afflicted areas. These relief measures were supplemented by auxiliary measures, such as exempting commodity taxes on grain shipped to disaster areas and punishing officials who failed to provide adequate disaster relief. The flood disasters disrupted the water system of the Grand Canal and forced the Qing government to transport Cao rice by sea beginning in 1826. This laid the groundwork for the rise of coastal shipping in modern China. With the economic recession of the 19th century, Chinese society was not as resilient to floods as it was in the 18th century. Compared to droughts, floods are more difficult to deal with and pose greater threats to infrastructure and to normal life and work in the cities.
\end{abstract}

\section{Hosted file}

Manuscript.doc available at https://authorea.com/users/396453/articles/509624-flooddisasters-and-social-resilience-during-the-decline-of-the-qing-dynasty-case-studiesof-1823-and-1849

\section{Hosted file}

Table 1.doc available at https://authorea.com/users/396453/articles/509624-flood-disastersand-social-resilience-during-the-decline-of-the-qing-dynasty-case-studies-of-1823-and1849 

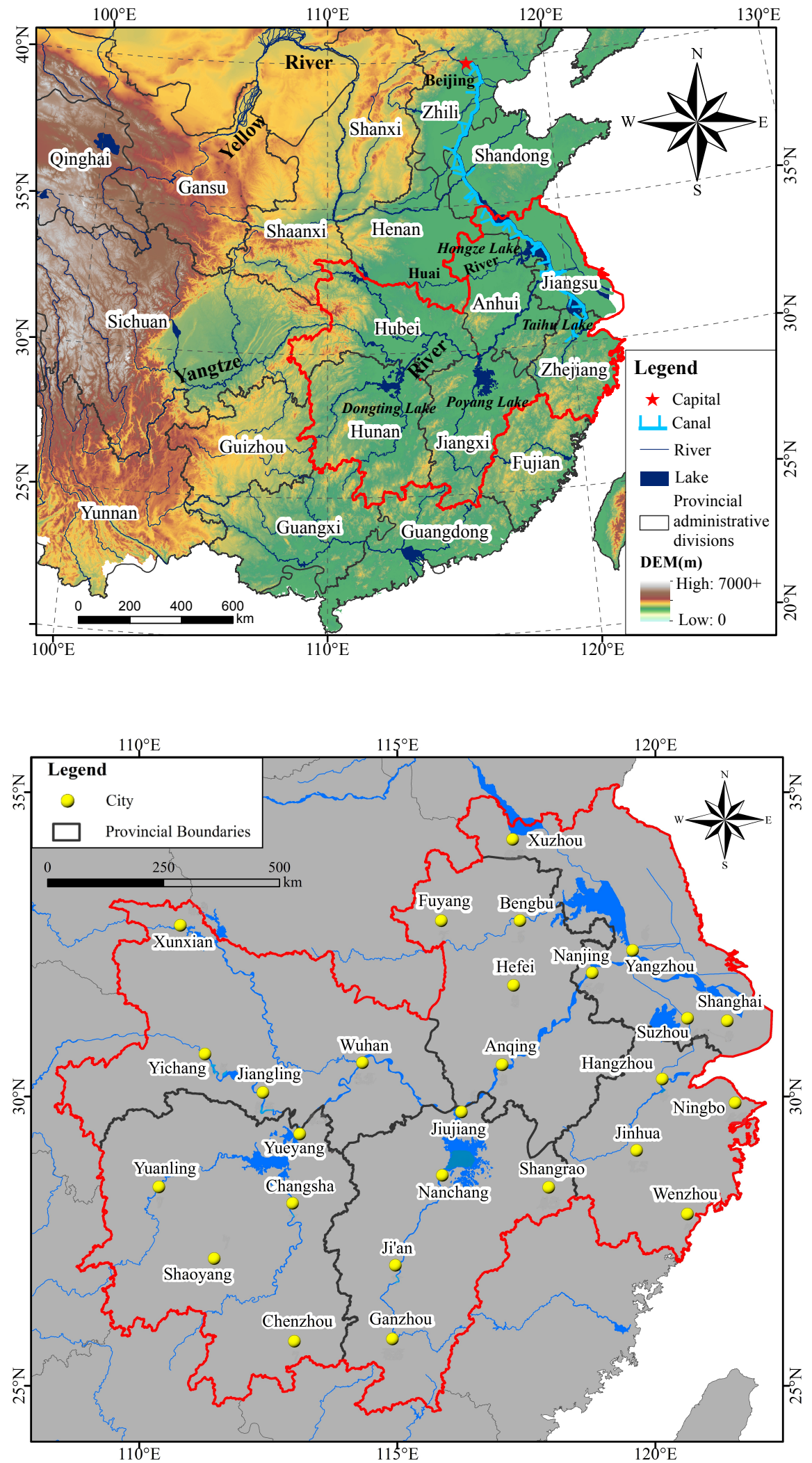

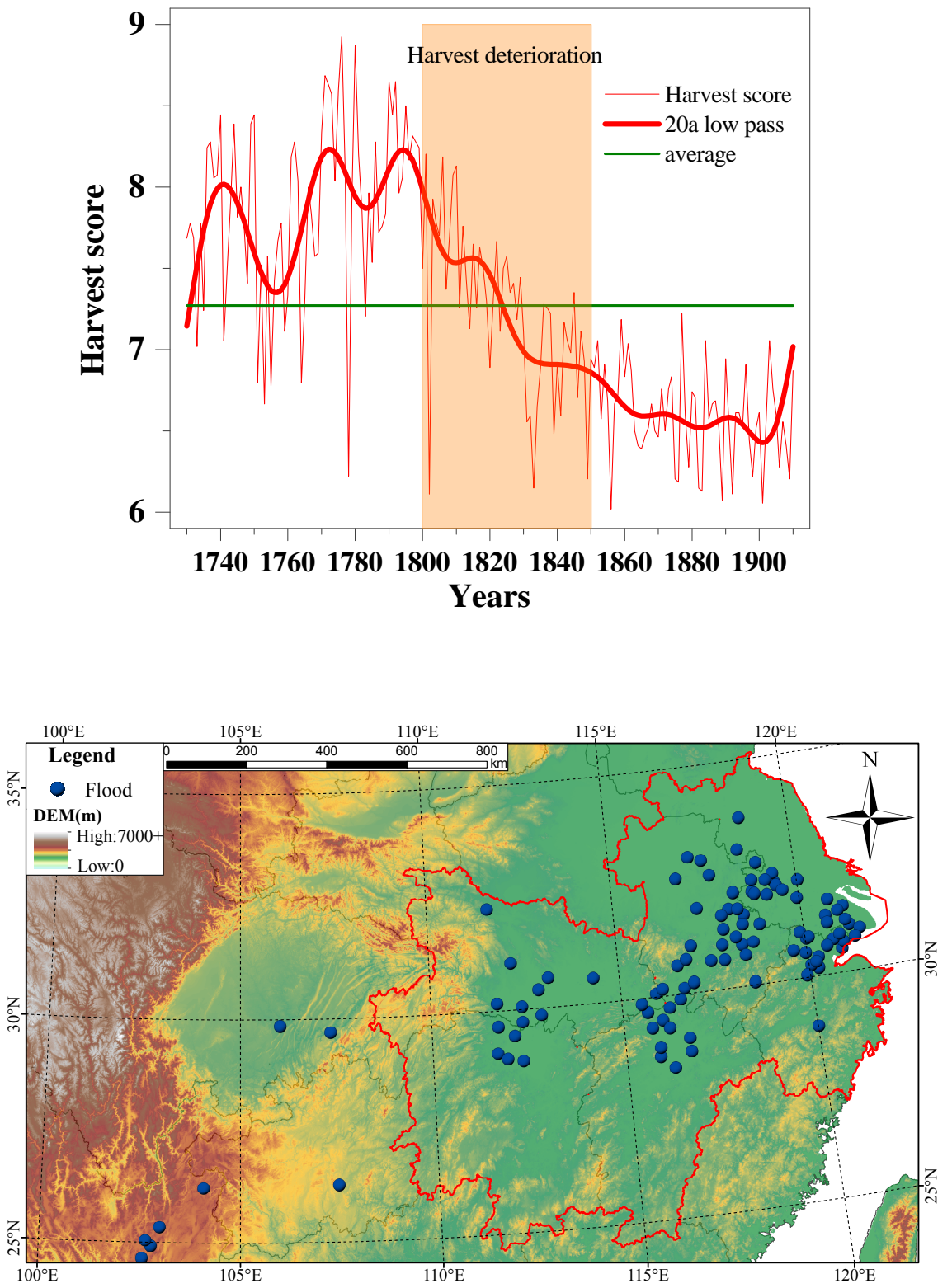

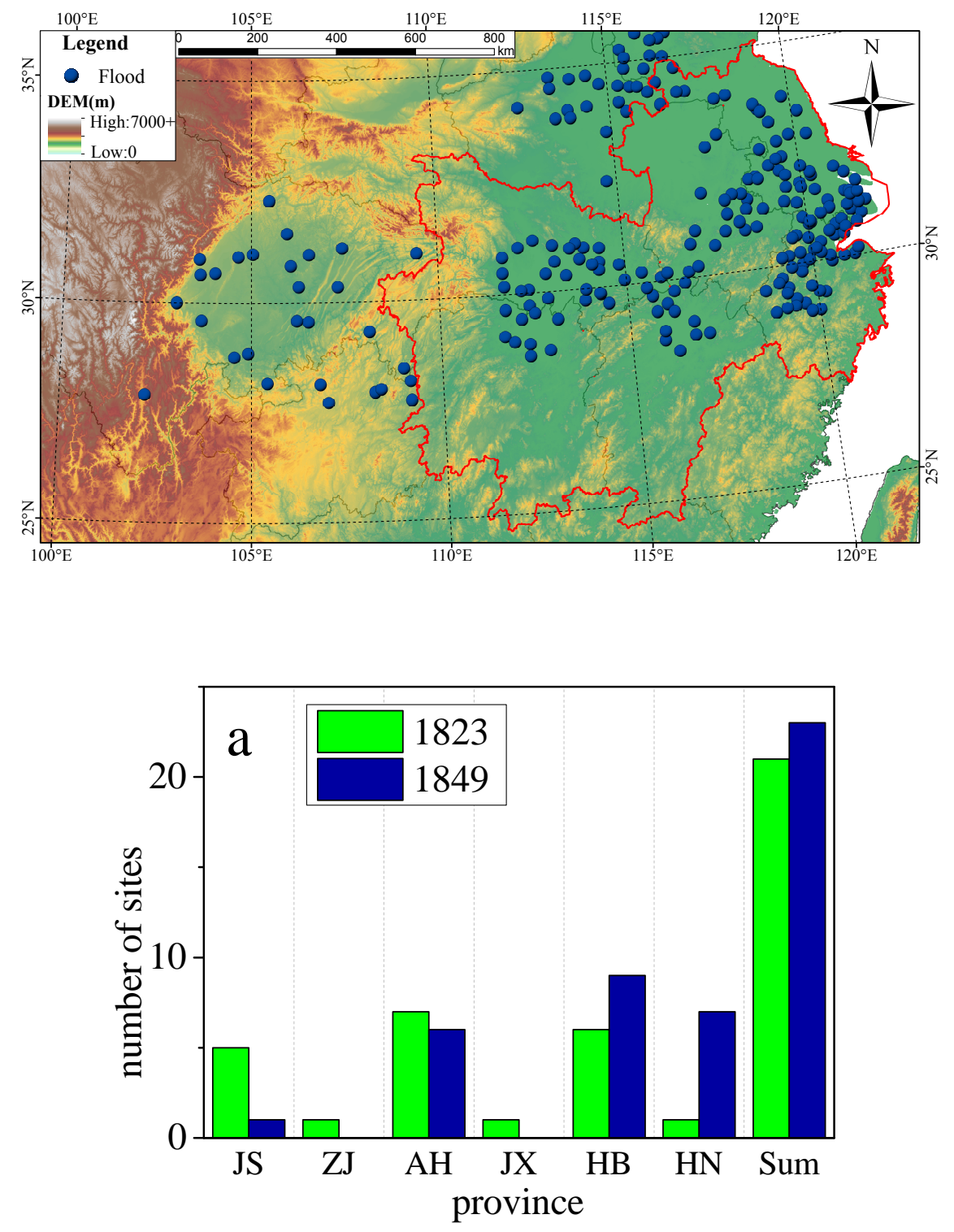

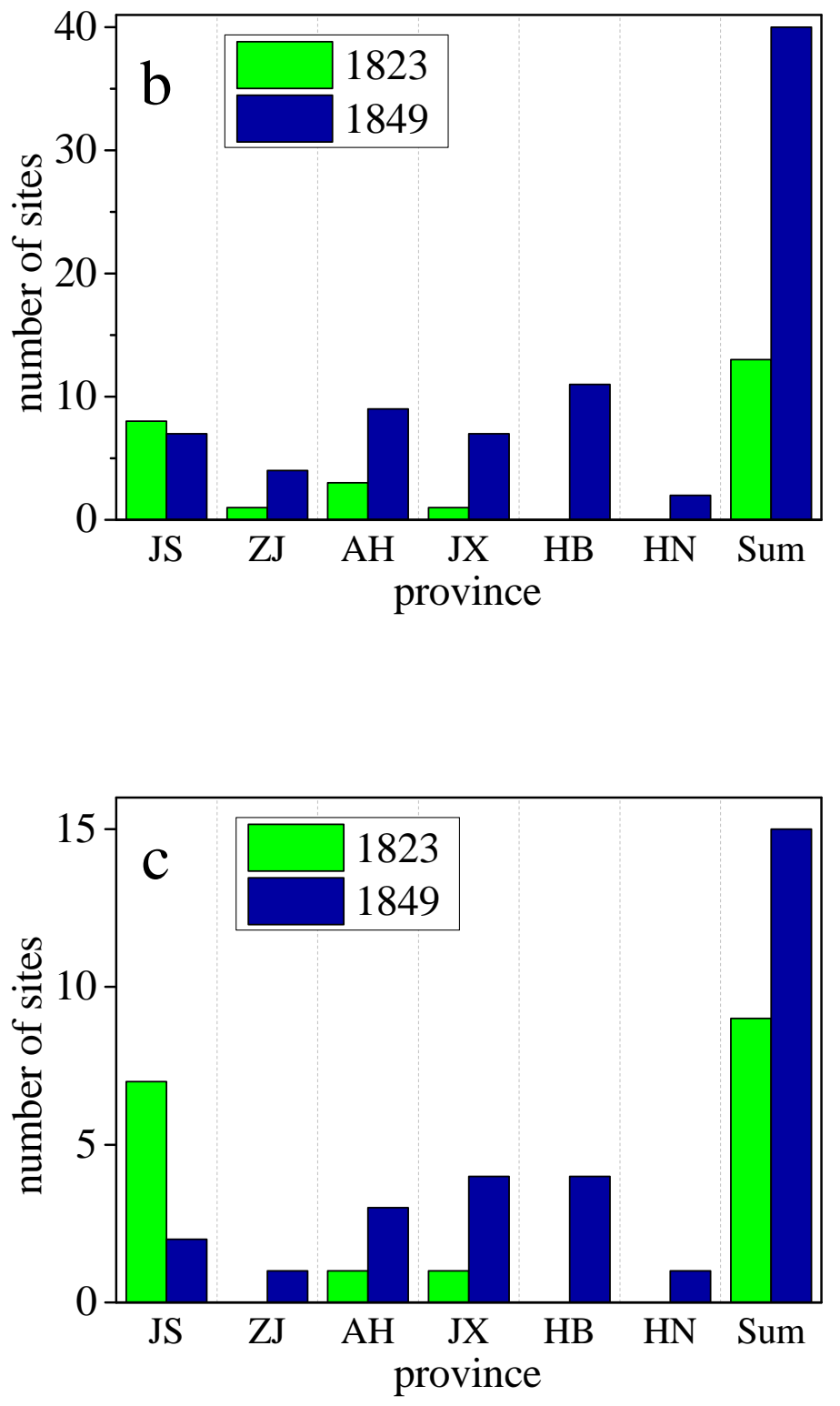

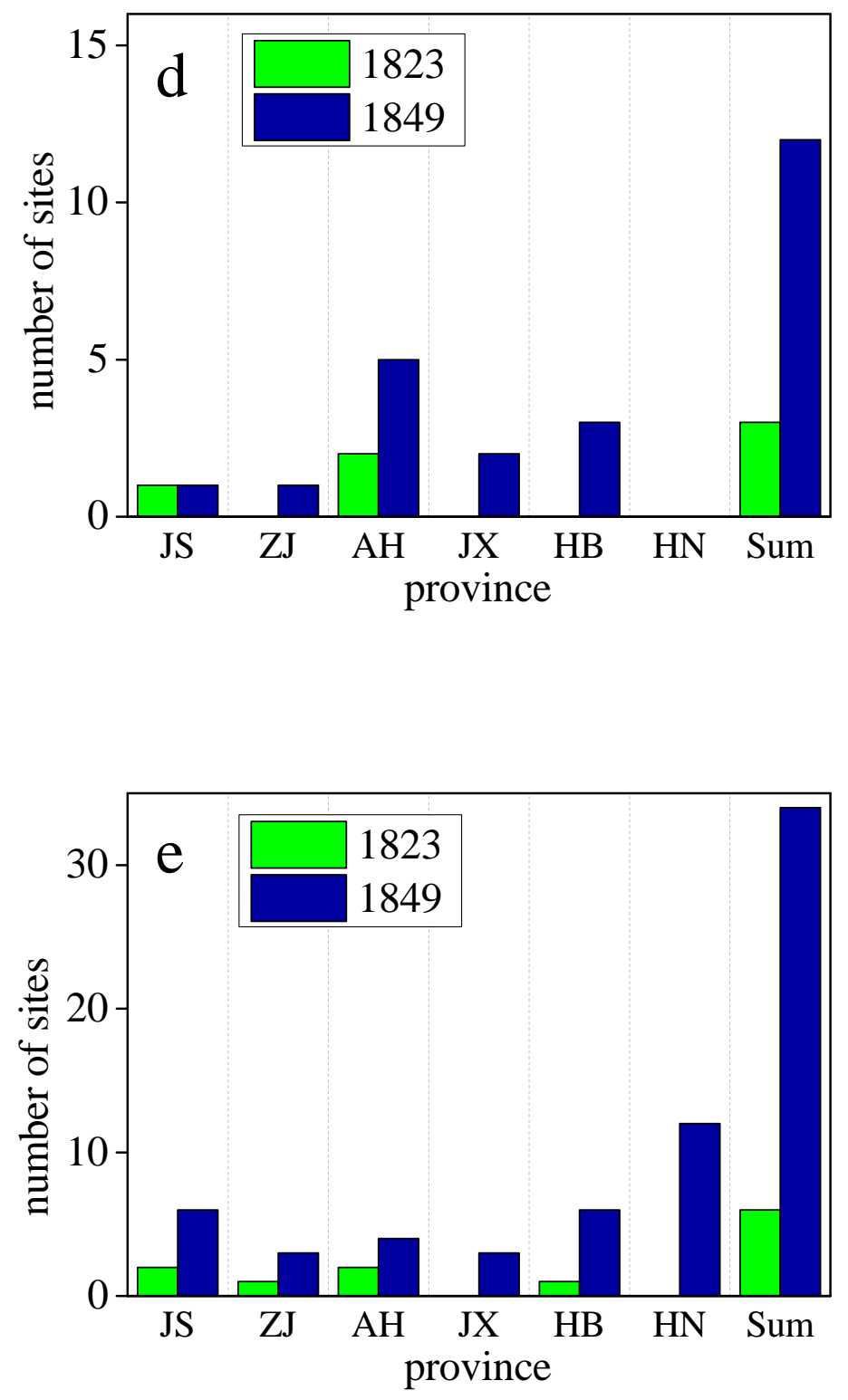

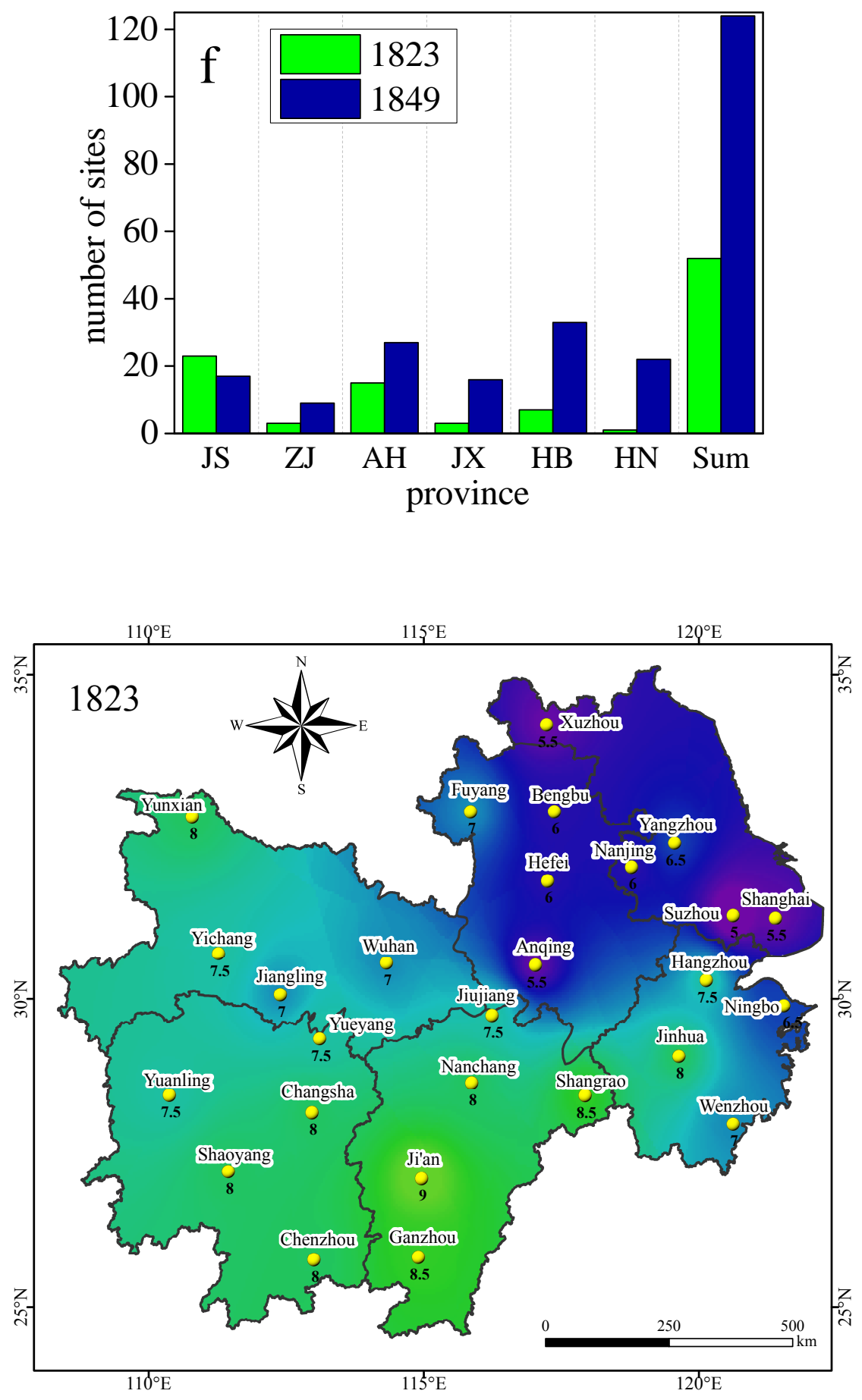

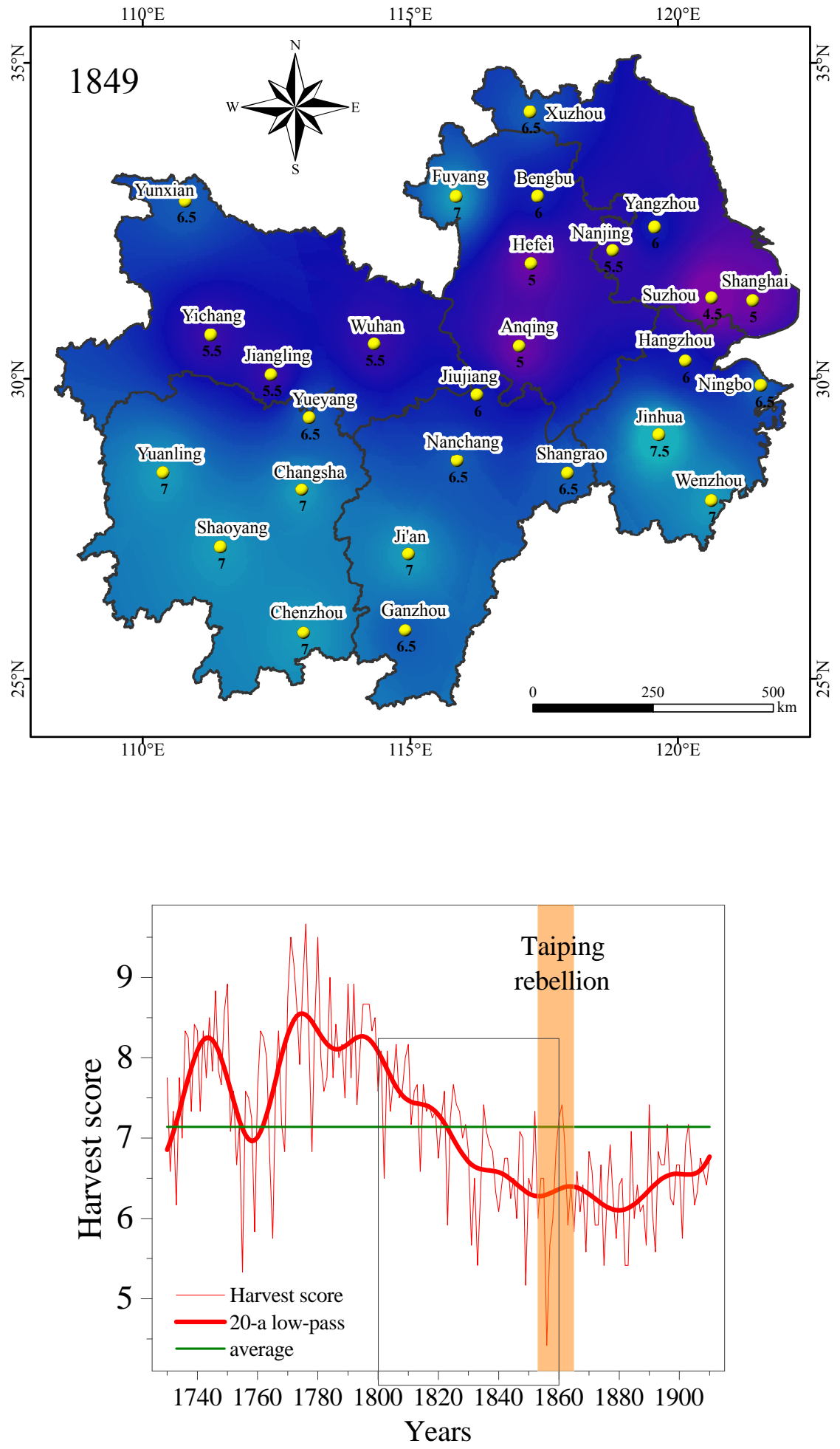

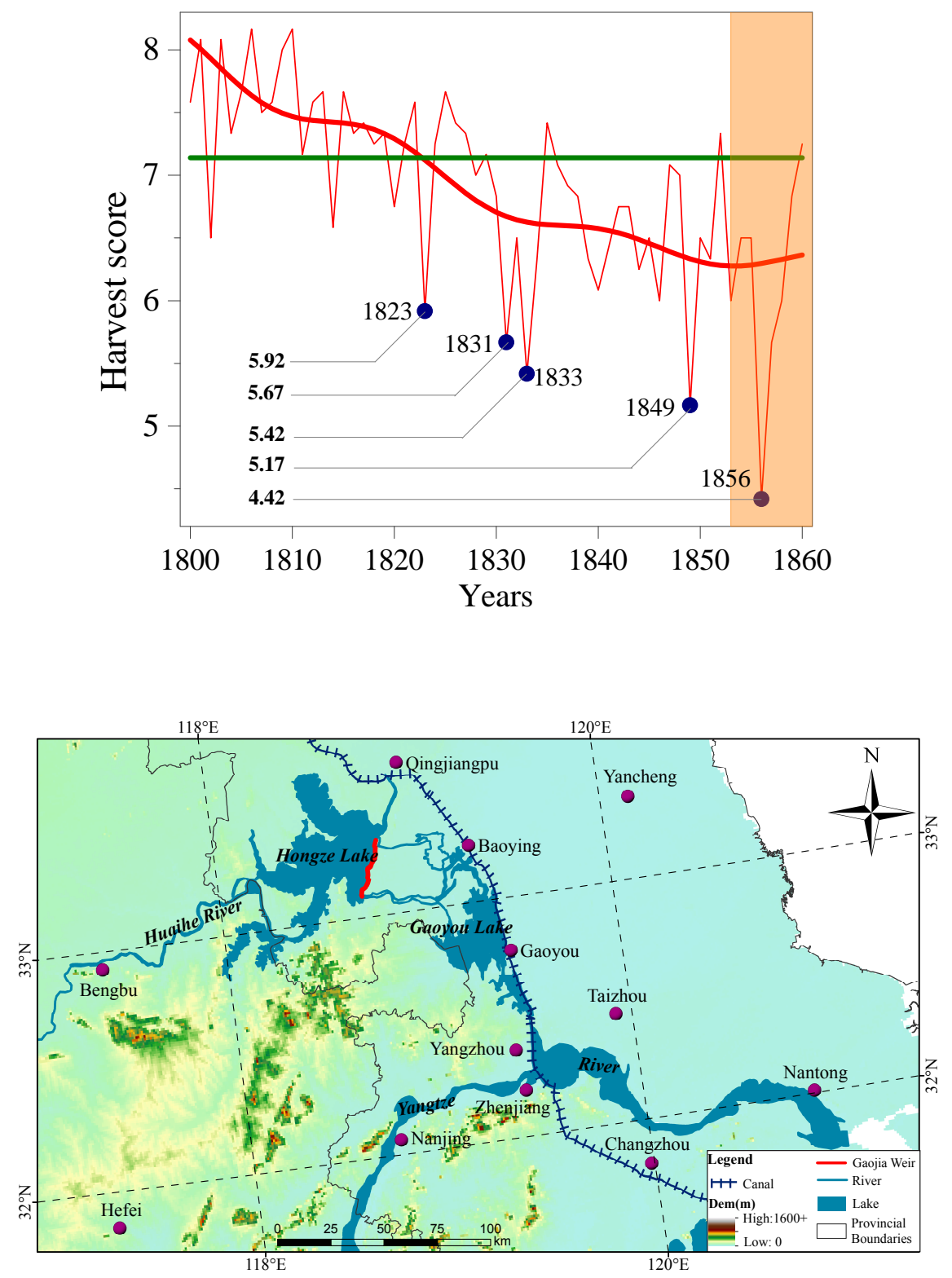

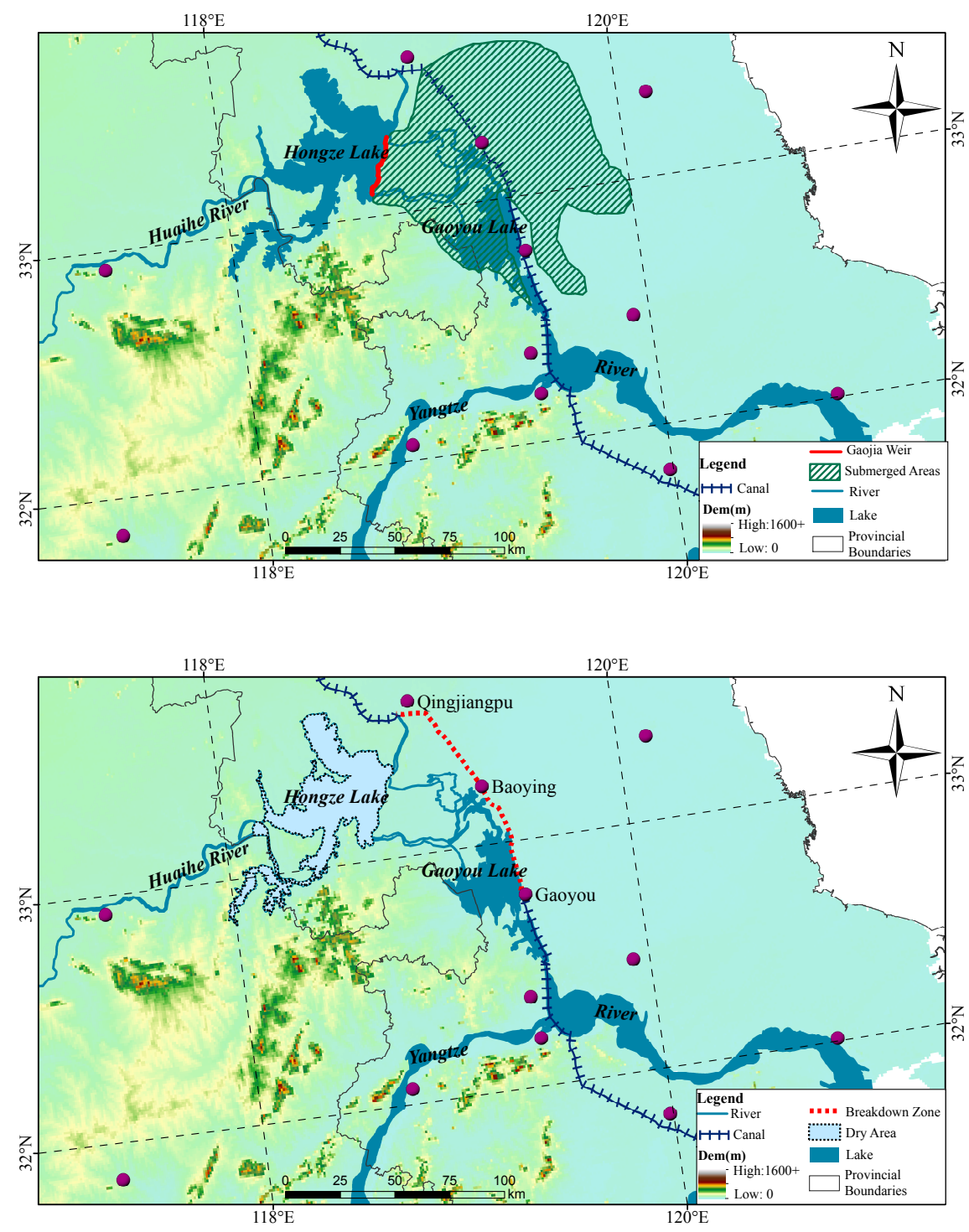


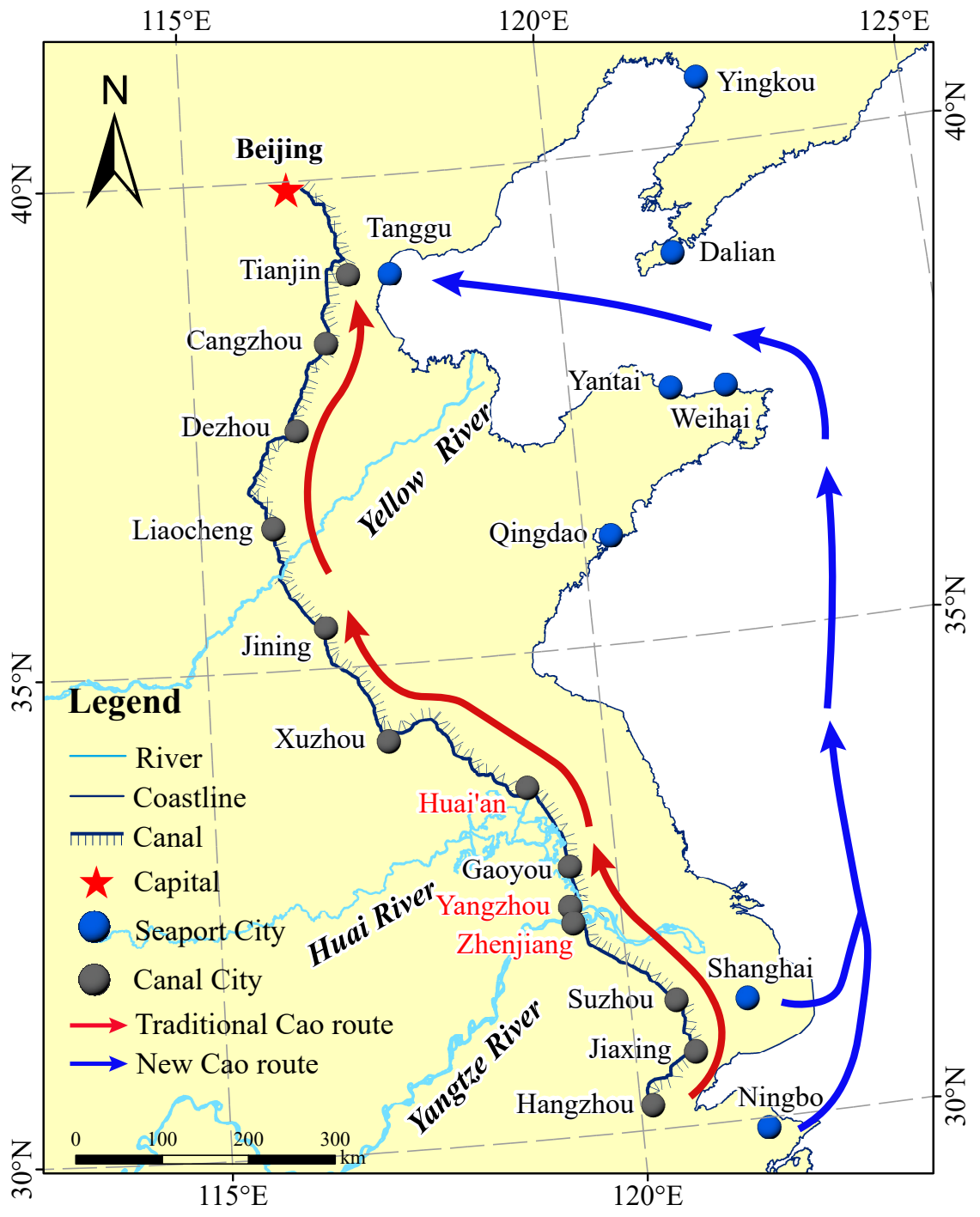

